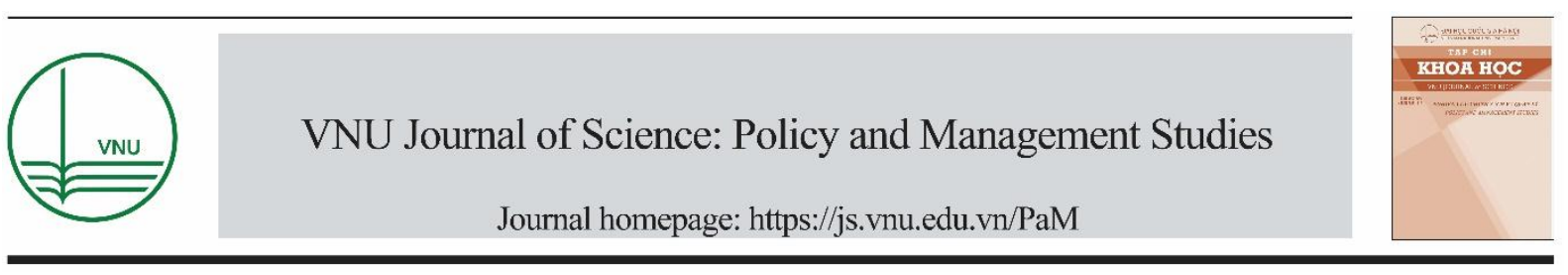

Review Article

\title{
Models of Public Debt Management in the World and Lessons for Vietnam
}

\author{
Pham Xuan Truong* \\ Faculty of International Economics, Foreign Trade University, 91 Chua Lang, Dong Da, Hanoi, Vietnam
}

Received 17 November 2020

Revised 25 November 2020; Accepted 03 December 2020

\begin{abstract}
Vietnam embarked on fundamentally building a public debt management system since 2009 as the Law of Public Debt Management was designed and promulgated. From then Vietnam has been following the typical model of public debt management used by developing countries, the market - based model which encompasses gradual building and completion of domestic market for government bond. However, because of several limitations in the national system of public debt management, the current model needs to be improved in alignment with the development level of Vietnam's economy. Especially, economic shocks such as the 2009 financial crisis or Covid 19 which has increased dramatically the scope of public debt also urge a more technical and effective model. The paper focuses on analyzing the practical models of public debt management in the world and subsequently the current situation of Vietnam's model. On that basis, the author figures out the limitations of the model and proposes a number of solutions to upgrade the model in accordance with the international practice regarding model of public debt management suitable with development level of economy.
\end{abstract}

Keywords: Public debt, sustainable public debt, public debt management, risk management, model of public debt management.

\footnotetext{
${ }^{*}$ Corresponding author.

Email address: truongpx@ftu.edu.vn
}

https://doi.org/10.25073/2588-1116/vnupam.4278 


\title{
Các mô hình quản lý nợ công trên thế giới và hàm ý chính sách cho Việt Nam
}

\author{
Phạm Xuân Trường \\ Khoa Kinh tế Quốc tế, Truờng Đại học Ngoại Thuoong, 91 Chùa Láng, Đống Đa, Hà Nội, Việt Nam \\ Nhận ngày 17 tháng 11 năm 2020 \\ Chỉnh sửa ngày 25 tháng 11 năm 2020; Chấp nhận đăng ngày 03 tháng 12 năm 2020
}

\begin{abstract}
Tóm tắt: Việt Nam bắt đầu thực hiện bài bản việc quản lý nợ công kể từ năm 2009 khi lần đầu tiên Luật quản lý nợ công được xây dựng và ban hành. Kể từ đó đến nay Việt Nam đi theo mô hình quản lý nợ công thường được các quốc gia đang phát triển áp dụng đó là mổ hình thị trường định hướng với việc dần dần xây dựng và hoàn thiện thị trường trái phiếu chính phủ. Tuy nhiên do một số hạn chế còn tồn tại trong hệ thống quản lý nợ công, mô hình hiện tại cần phải được cải thiện để tương thích với trình độ phát triển của nền kinh tế. Đặc biệt các cú sốc kinh tế mới đây như khủng hoảng kinh tế 2009, dịch Covid19 khiến quy mô nợ cồng gia tăng đột biến đòi hỏi một mô hình quản lý nợ công kỹ trị và hiệu quả hơn. Bài viết phân tích các mô hình quản lý nợ công trên thế giới, sau đó tập trung phân tích thực trạng mô hình quản lý nợ công hiện tại của Việt Nam. Trên cơ sở đó, tác giả chỉ ra những hạn chế trong mô hình này và đề xuất một số giải pháp nhằm nâng cấp mô hình hiện tại sao cho phù hợp với thông lệ trên thế giới về quản lý nợ công theo trình độ phát triển của nền kinh tế.
\end{abstract}

Tư khóa: Nợ công, nợ công bền vững, quản lý nợ công, quản trị rủi ro, mô hình quản lý nợ công.

\section{Mở đầu}

Nợ công từ lâu đã trở thành mối quan tâm hàng đầu của các chính phủ trong vấn đề ổn định kinh tế vĩ mô. Một quốc gia có nợ công cao, khả năng thanh toán bấp bênh không thể duy trì một môi trường vĩ mô ổn định cho nền kinh tế. Ngược lại, một quốc gia nợ công ở mức vừa phải, có khả năng thanh toán tốt các khoản nợ đến hạn thường sẽ có một môi trường vĩ mô ổn định. Mô hình quản lý nợ công hiệu quả là một yếu tố rất quan trọng để đảm bảo trạng thái nợ công khỏe mạnh, từ đó đảm bảo cho nền kinh tế có một nền tảng vĩ mô tốt. Trên thế giới có rất nhiều mô hình quản lý nợ công đã được các chính phủ các quốc gia áp dụng như mô hình quản lý nợ công có cơ

\footnotetext{
*Tác giả liên hệ.

Địa chi email: truongpx@ ftu.edu.vn

https://doi.org/10.25073/2588-1116/vnupam.4278
}

quan chuyên biệt trực thuộc Bộ Tài chính (BTC) với mô hình quản lý nợ công có cơ quan chuyên biệt độc lập; mô hình quản lý nợ công có chiến lược với mô hình quản lý nợ công không có chiến lược, ,... Mỗi một mô hình quản lý nợ công như vậy lại phù hợp với trình độ phát triển nhất định của nền kinh tế. Bài viết sẽ chỉ ra các mô hình quản lý nợ công đang được thực hiện trên thế giới, từ đó xác định Việt Nam đang thực hiện mô hình quản lý nợ công nào và Việt Nam cần phải làm gì để nâng cấp mô hình quản lý nợ công nhằm khắc phục những hạn chế của mô hình hiện tại. 


\section{Quản lý nợ công và các mô hình quản lý nọ̣ công trên thế giới}

Quản lý trong khoa học quản trị là "một quá trình lập kế hoạch, tổ chức, hướng dẫn và kiểm tra những nỗ lực của các thành viên trong một tổ chức và sử dụng các nguồn lực của tổ chức để đạt được những mục tiêu cụ thể" [1]. Nợ công là toàn bộ nợ của chính phủ trung ương, chính quyền địa phương và các tổ chức trực thuộc cùng với nợ do chính phủ bảo lãnh [2]. Tùy quy định pháp luật của từng nước mà nợ công còn bao gồm nợ của các doanh nghiệp nhà nước (phần nợ không được chính phủ bảo lãnh), phần vốn đối ứng của nhà nước trong các dự án đối tác công tư (Public Private Partnership - PPP), nợ của ngân hàng trung ương và nợ của quỹ bảo hiểm xã hội quốc gia [2]. Như vậy quản lý nợ công xét theo nghĩa kêt hợp của hai từ quản lý và nợ công có thể hiểu là hoạt động thu thập, theo dõi, phân tích đánh giá số liệu và cuối cùng đưa ra kế hoạch và tổ chức thực hiện kế hoạch điều chỉnh các khoản nợ được coi là nợ công theo luật quốc gia nhằm đạt được những mục tiêu đã định sẵn. Phạm vi quản lý nợ công phụ thuộc vào phạm vi định nghĩa nợ công của từng quốc gia. Cách hiểu này khá tương đồng với khái niệm quản lý nợ công phổ biến của Quỹ tiền tệ quốc tế (IMF) và Ngân hàng thế giới (WB): quản lý nợ công là quá trình thiết lập và thực hiện một chiến lược để quản lý nợ chính phủ nhằm đáp ứng nguồn quỹ tài trợ cho chi tiêu công ở mức chi phí thấp nhất trong trung và dài hạn dựa trên một mức độ rủi ro hợp lý [3]. Trong khái niệm này, IMF và $\mathrm{WB}$ đã đi xa hơn khi chỉ ra mục tiêu chung của quản lý nợ công đó là tối thiểu hóa chi phí khi chính phủ vay nợ trong điều kiện đã xác định được mức độ rủi ro phù hợp.

Có thể thấy trọng tâm của khái niệm phổ biến về quản lý nợ công do IMF và $\mathrm{WB}$ đưa ra là chiến lược quản lý nợ công. Chiến lược quản lý nợ công có thể hiểu là một kế hoạch trung và dài hạn đề ra phương hướng giúp chính phủ đạt được các mục tiêu quản lý nợ [4]. Một chiến lược tổng quan nói chung và chiến lược nợ công nói riêng sẽ bao gồm các thành phần như tính cần thiết, mục tiêu, nhiệm vụ, giải pháp và kế hoạch hành động. Nhìn chung đây chính là khía cạnh nội dung trong quản lý nợ công. Tuy nhiên nội dung của quản lý nợ công là không đủ để hình thành một hệ thống đầy đủ về quản lý nợ công trong đó cần phải có các thành phần như khung pháp lý, cơ cấu tổ chức các cơ quan thực hiện chức năng quản lý nhà nước về nợ công và cơ chế phối hợp với các chính sách khác có liên quan (chính sách tài khóa (CSTK), chính sách tiền tệ (CSTT)). Tất cả những thành phần trên tạo nên mô hình quản lý nợ công. Như vậy, có thể hiểu mô hình quản lý nợ công là một hệ thống có tổ chức của nhà nước nhằm thực thi quyền hạn quản lý nợ công theo luật định để đạt được một số mục tiêu nhất định. Sự phân loại trong một thành phần của mô hình và các cách kết hợp khác nhau giữa chúng sẽ tạo nên những mô hình quản lý nợ công khác nhau. Sau đây là nội dung cụ thể của các thành phần trong mô hình quản lý nợ công:

- Cơ sở pháp lý: bao gồm điều ước quốc tế liên quan đến nợ công nếu quốc gia nằm trong một liên minh kinh tế hoặc liên minh tiền tệ; luật quốc gia liên quan đến quản lý, giám sát nợ công, ngân sách; nghị định thông tư hướng dẫn chi tiết của chính phủ và các cơ quan thuộc chính phủ liên quan đến các bộ luật kể trên.

- Cơ cấu tổ chức: các quốc gia có thể duy trì có hoặc không có một cơ quan chuyên biệt để quản lý nợ công (Debt Management Office DMO). Nếu không có một cơ quan chuyên biệt thì chức năng quản lý nợ công thường được đảm nhiệm bởi các bộ phận phụ trách chi tiêu vay nợ ở từng bộ ban ngành (Canada, Mỹ). Đây được gọi là cách thức tổ chức phi tập trung. Cách thức tồ chức phi tập trung chỉ phù hợp với các quốc gia có khung pháp lý chặt chẽ, thông tin về nợ công đầy đủ, cập nhật, minh bạch và nguồn nhân lực quản trị tốt [5]. Nếu có một cơ quan chuyên biệt thì cơ quan này hoặc độc lập với các bộ ban ngành và trực tiếp trực thuộc chính phủ (Ai Len, Đức, Thụy Điển, Hungary) hoặc cơ quan này là một bộ phận của BTC (Bỉ, Pháp, Ý, Hà Lan, Tây Ban Nha, Anh, Úc) hoặc Ngân hàng trung ương (NHTW) (Đan Mạch). Đây được gọi là cách thức tổ chức tập trung. Mỗi một cách thức tổ chức $\mathrm{DMO}$ đều có ưu nhược điểm riêng tuy nhiên cách thức tổ chức DMO độc lập hoặc là một bộ 
phận của Bộ tài chính được lựa chọn nhiều hơn cả do mức độ gần gũi giữa chính sách quản lý nợ công và chính sách tài khóa [5]. Thông thường trong trường hợp các quốc gia có DMO thì cơ cấu tổ chức của DMO sẽ phải có ba bộ phận chính là bộ phận hỗ trợ (back-office) phụ trách ghi chép, báo cáo và xây dựng phương án trả nợ, bộ phận chuyển tiếp (middle - office) phụ trách việc phân tích, giám sát và kiểm soát các hoạt động vay nợ và bộ phận vận hành (front - office) trực tiếp thực hiện các giao dịch liên quan đến vay, trả nợ công và duy trì quan hệ với các nhà đầu tư [6].

- Nội dung quản lý nợ công: là hoạt động theo dõi, phân tích đánh giá và đưa ra kế hoạch hành động liên quan đến nợ công để đạt được mục tiêu định sẵn. Nội dung này có thể nêu ra dưới dạng văn bản hoặc không. Trong trường hợp nội dung được thể hiện dưới dạng văn bản thì đó chính là chiến lược quản lý nợ công. Thông thường các chiến lược nợ công sẽ có mục tiêu tối thiểu hóa chi phí khi vay nợ trong trung hạn. Đây là quan điểm bảo hiểm tài khóa truyền thống khi tạo ra vị thế nợ quốc gia có thể chống chịu được với các cú sốc, qua đó ngăn ngừa việc điều chỉnh lớn các chương trình về chi tiêu công hoặc thuế suất [7] giúp duy trì lãi suất, lạm phát ổn định [8]. Hiện tại, phần lớn các nhà quản lý nợ công đều đồng ý với mục tiêu được đưa ra trong định nghĩa về quản lý nợ công của IMF và WB đó là đảm bảo cho nhu cầu tài trợ chi tiêu của chính phủ và nghĩa vụ trả nợ được đáp ứng ở mức chi phí thấp nhất trong ngắn hạn và dài hạn dựa trên mức độ rủi ro hợp lý ${ }^{1}$. Đây được coi là mục tiêu tổng hòa các mục tiêu truyền thống liên quan đến thuế suất, lãi suất và lạm phát, đồng thời xét đến cả giảm thiểu rủi ro liên quan đến nợ công như rủi ro thị trường, rủi ro đảo nợ.

- Phối hợp với các chính sách khác: Hai thập kỷ trước đây, quản lý nợ công được nhìn như là một phần mở rộng của chính sách tiền tệ hoặc chính sách tài khóa [9]. Nó không được đánh giá

\footnotetext{
${ }^{1}$ Rủi ro liên quan đến quản lý nợ công bao gồm rủi ro thị trường (rủi ro lãi suất, rủi ro tỷ giá), rủi ro thanh khoản, rủi ro tín dụng, rủi ro thanh toán và rủi ro điều hành.
}

như một chính sách vĩ mô riêng biệt và thường được giao nhiệm vụ hỗ trợ các chính sách vĩ mô khác. Trong suốt thời gian đó, nhiệm vụ quản lý nợ công thường nằm trong tay các quan chức tài chính, tiền tệ. Kể từ cuối năm 1980 và trong suốt 1990, thiết lập thể chế cho hoạt động quản lý nợ công đã trải qua một sự chuyển biến lớn ở một số nước $\mathrm{OECD}[10]$. Sự lo ngại này đến từ thảo luận về mục tiêu của các chính sách vĩ mô khác nhau và sự đánh đổi giữa chúng. Mở rộng tài khóa hỗ trợ nền kinh tể làm gia tăng quy mô nợ công và rủi ro có liên quan mâu thuẫn với mục tiêu nợ công ổn định của chính sách quản lý nợ công. Chính sách tiền tệ kiểm soát lạm phát có xu hướng giữ lãi suất cao mâu thuẫn với mục tiêu giảm chi phí vay nợ của chính sách quản lý nợ công. Ngược lại một chính sách tiền tệ mở rộng làm giảm lãi suất lại dẫn đến vay nợ nhiều hơn từ đó làm gia tăng quy mô nợ công. Ngoài ra, việc chính sách tiền tệ có thể can thiệp vào tỷ giá cũng có thể làm thay đổi cơ cấu nợ nước ngoài trong tổng nợ công. Theo chiều ngược lại, quản lý nợ công cứng nhắc có thể sẽ không phù hợp trong thời kỳ nền kinh tế suy thoái phải dựa nhiều vào chính sách tài khóa mở rộng; quản lý nợ công quá lỏng lẻo lại dẫn đến nợ gia tăng làm phát sinh kỳ vọng về lạm phát và lãi suất cao, từ đó ảnh hưởng tới chính sách tài khóa và tiền tệ. Dần dần việc thừa nhận xung đột trong lợi ích và nhận thức sâu sắc hơn về vấn đề các chính sách khác nhau nên được quản lý bởi các cơ quan khác nhau của các chính phủ đã mở đường cho sự độc lập của $\mathrm{NHTW}$ và tương ứng là sự tự chủ gia tăng cho cơ quan quản lý nợ công [10]. Hiện nay có thể nói chính sách quản lý nợ công có sự gắn kết chặt chẽ với chính sách tài khóa do bản chất của hai chính sách này đều liên quan đến thuế và chi tiêu chính phủ và phần lớn các chính phủ đều hướng tới môi trường tài khóa bền vững. Ngược lại sự kết hợp giữa chính sách quản lý nợ công và chính sách tiền tệ ngày càng mờ nhạt do chính sách tiền tệ dần trở nên độc lập và đối tượng quản lý chính của chính sách tiền tệ độc 
lập lại là cung tiền. Ngoài ra, cách thức tổ chức cơ quan quản lý nợ công đã hàm ý về sự phối hợp chính sách: nếu đặt trong BTC thì hàm ý phối hợp với chính sách tài khóa, NHTW thì hàm ý phối hợp với NHTW. Vì thực tế cho thấy chính sách quản lý nợ công phối hợp chặt chẽ hơn với chính sách tài khóa nên cơ quan quản lý nợ công chuyên biệt trực thuộc một bộ nếu có thường nằm trong $\mathrm{BTC}$.

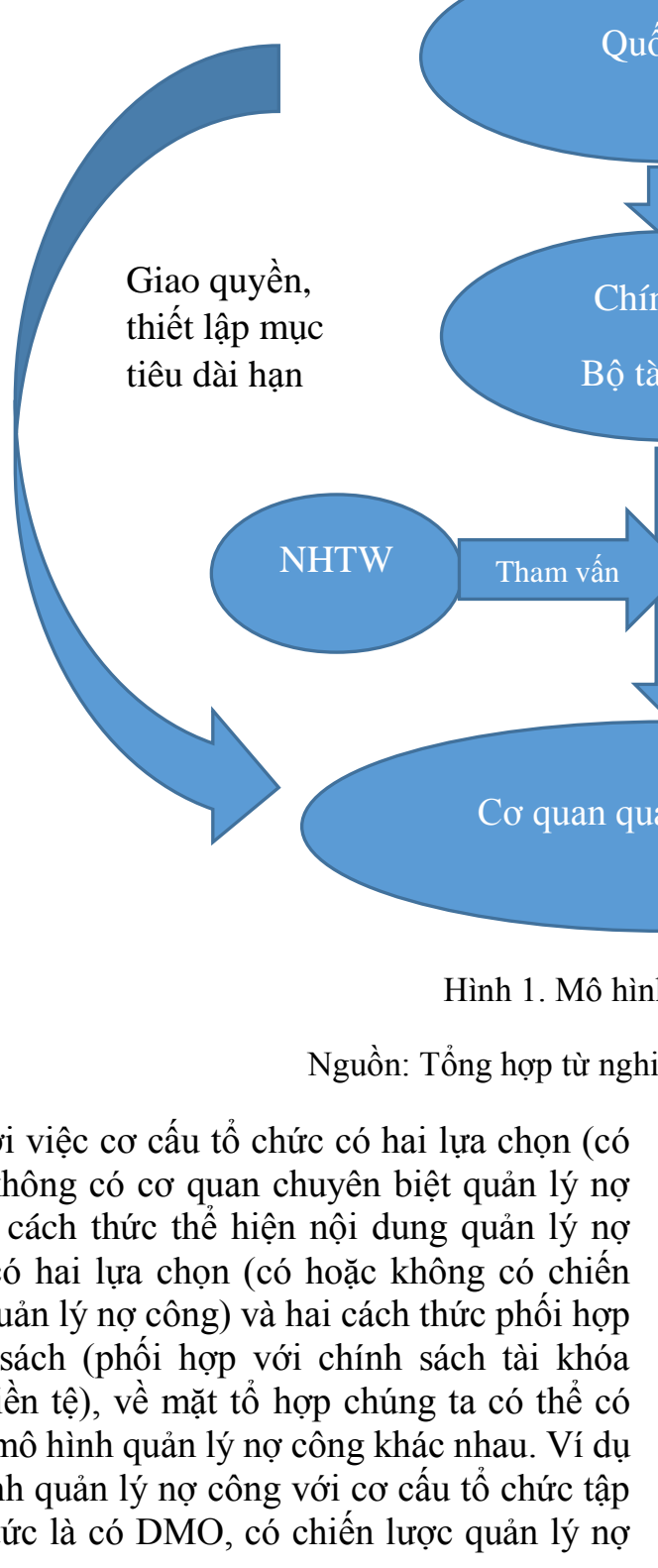

công, chính sách quản lý nợ công phối hợp chặt chẽ với chính sách tài khóa; mô hình quản lý nợ công với cơ cấu tổ chức phi tập trung tức là không có $\mathrm{DMO}$, không có chiến lược quản lý nợ công, chính sách quản lý nợ công phối hợp chặt chẽ với chính sách tiền tệ. Tuy nhiên trên thực tế chỉ có vài dạng mô hình quản lý nợ công phù hợp với điều kiện thực tế của từng nhóm nước. Vậy đó là những mô hình nào?

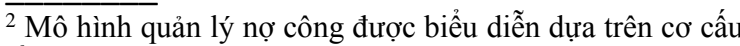
tổ chức thường gặp đó là cơ quan quản lý nợ công trực thuộc BTC
} 
Bảng 1. Một số mô hình quản lý nợ công ở các nước trên thế giới

\begin{tabular}{|c|c|c|c|c|}
\hline & $\begin{array}{l}\text { Cơ quan quản } \\
\text { lý nợ công }\end{array}$ & $\begin{array}{l}\text { Chiến lược quản } \\
\text { lý nợ công tồng } \\
\text { thể }\end{array}$ & Mục tiêu & $\begin{array}{l}\text { U’u tiên } \\
\text { phối hợp } \\
\text { chính } \\
\text { sách }\end{array}$ \\
\hline Úc & $\begin{array}{l}\text { Trực thuộc } \\
\text { BTC }\end{array}$ & Có & $\begin{array}{l}\text { Danh mục nợ công phải được thiết lập với chi } \\
\text { thấp nhất trong dài hạn, tương ứng với mức } \\
\text { rủi ro chấp nhận được }\end{array}$ & CSTK \\
\hline $\begin{array}{l}\text { Đan } \\
\text { Mạch }\end{array}$ & $\begin{array}{l}\text { Trực thuộc } \\
\text { NHTW }\end{array}$ & Có & $\begin{array}{l}\text { Vay được ở mức chi phí thấp nhất trong dài } \\
\text { hạn; duy trì rủi ro chấp nhận được; xây dựng } \\
\text { và hồ trợ một thị trường tài chính hoạt động } \\
\text { tốt, hiệu quả }\end{array}$ & CSTT \\
\hline Ai Len & $\begin{array}{l}\text { Cơ quan độc } \\
\text { lập }\end{array}$ & Có & $\begin{array}{l}\text { Duy trì mức độ ổn định của nghĩa vụ nợ phải } \\
\text { trả hàng năm; giảm thiểu rủi ro nợ của chính } \\
\text { phủ }\end{array}$ & $\begin{array}{l}\text { CSTK và } \\
\text { CSTT }\end{array}$ \\
\hline $\begin{array}{l}\text { Niu Di } \\
\text { Lân }\end{array}$ & $\begin{array}{l}\text { Trực thuộc } \\
\text { BTC }\end{array}$ & $\begin{array}{l}\text { Không có, chỉ có } \\
\text { văn bản hướng } \\
\text { dẫn quy trình, } \\
\text { cách thức quản lý } \\
\text { nợ công }\end{array}$ & $\begin{array}{l}\text { Tối đa hóa thu nhập tài sản tài chính của nợ } \\
\text { chính phủ; duy trì rủi ro nợ công thấp nhât có } \\
\text { thể }\end{array}$ & CSTK \\
\hline $\begin{array}{l}\text { Bồ Đào } \\
\text { Nha }\end{array}$ & $\begin{array}{l}\text { Trực thuộc } \\
\text { BTC }\end{array}$ & Có & $\begin{array}{l}\text { Đảm bảo đủ quỹ cho hoạt động của chính phủ, } \\
\text { nợ công ở mức ổn định và tối thiểu hóa chi phí } \\
\text { nợ chính phủ trong dài hạn }\end{array}$ & CSTK \\
\hline $\begin{array}{l}\text { Thừ } \\
\text { Điền }\end{array}$ & $\begin{array}{l}\text { Cơ quan độc } \\
\text { lập }\end{array}$ & $\begin{array}{l}\text { Không có, chỉ có } \\
\text { văn bản hướng } \\
\text { dẫn quy trình, } \\
\text { cách thức quản lý } \\
\text { nợ công }\end{array}$ & $\begin{array}{l}\text { Tối thiếu hóa chi phí trong dài hạn gắn với rủi } \\
\text { ro của từng phương thức tài trợ }\end{array}$ & CSTT \\
\hline Anh & $\begin{array}{l}\text { Trực thuộc } \\
\text { BTC }\end{array}$ & Có & $\begin{array}{l}\text { Tối thiểu hóa chi phí trong dài hạn; hằng năm } \\
\text { điều chỉnh các khoản vay nợ theo tiêu chuẩn } \\
\text { định sẵn }\end{array}$ & CSTK \\
\hline Đức & $\begin{array}{l}\text { Cơ quan độc } \\
\text { lập }\end{array}$ & Không có & $\begin{array}{l}\text { Đảm bảo an toàn danh mục tài sản - nợ trong } \\
\text { tài chính quốc gia, duy trì lãi suất đi vay thâpp } \\
\text { nhất trong trung và dài hạn cùng với việc kiểm } \\
\text { soát các rủi ro }\end{array}$ & CSTK \\
\hline $\begin{array}{l}\text { Tây Ban } \\
\text { Nha }\end{array}$ & $\begin{array}{l}\text { Trực thuộc } \\
\text { BTC }\end{array}$ & Có & $\begin{array}{l}\text { Củng cố vị thế tài khóa dựa trên mục tiêu tăng } \\
\text { trưởng tối thiểu }\end{array}$ & CSTK \\
\hline Canada & Không có & Có & $\begin{array}{l}\text { Duy trì chi phí thấp ổ định cho các khoản } \\
\text { vay của chính phủ và thị trường trái phiếu } \\
\text { chính phủ trong nước khỏe mạnh }\end{array}$ & $\begin{array}{l}\text { CSTK và } \\
\text { CSTT }\end{array}$ \\
\hline $\begin{array}{l}\text { Xinh-ga- } \\
\text { po }\end{array}$ & Không có & Không có & $\begin{array}{l}\text { Đảm bảo chi tiêu, vay nợ của chính phủ phục } \\
\text { vụ cho chính sách tăng trường }\end{array}$ & CSTK \\
\hline $\begin{array}{l}\text { In-đô-nê- } \\
\text { si-a }\end{array}$ & $\begin{array}{l}\text { Trực thuộc } \\
\text { BTC }\end{array}$ & Có & $\begin{array}{l}\text { Tối thiểu hóa chi phí đi vay trong mức độ rủi } \\
\text { ro có thể chấp nhận được }\end{array}$ & CSTK \\
\hline $\begin{array}{l}\text { Phi-líp- } \\
\text { pin }\end{array}$ & $\begin{array}{l}\text { Cơ quan độc } \\
\text { lập }\end{array}$ & Có & $\begin{array}{l}\text { Duy trì danh mục nợ bền vững với chi phí và } \\
\text { rủi ro ở mức chấp nhận được; phát triển thị } \\
\text { trường vốn trong nước }\end{array}$ & $\begin{array}{l}\text { CSTK và } \\
\text { CSTT }\end{array}$ \\
\hline Kenya & $\begin{array}{l}\text { Trực thuộc } \\
\text { BTC }\end{array}$ & Có & $\begin{array}{l}\text { Giữ nợ công ổn định trong điều kiện chi phí đi } \\
\text { vay vấc độ rủi ro tối thiểu }\end{array}$ & CSTK \\
\hline
\end{tabular}




\begin{tabular}{|l|l|l|l|l|}
\hline $\begin{array}{l}\text { Sri } \\
\text { Lanka }\end{array}$ & $\begin{array}{l}\text { Trực thuộc } \\
\text { NHTW }\end{array}$ & Có & $\begin{array}{l}\text { Giảm thiểu chi phí trực tiếp, gián tiếp của nợ } \\
\text { công trong dài hạn; thúc đây hiệu quả thị } \\
\text { trường trái phiếu chính phủ }\end{array}$ & $\begin{array}{l}\text { CSTT và } \\
\text { CSTK }\end{array}$ \\
\hline Liberia & $\begin{array}{l}\text { Trực thuộc } \\
\text { BTC }\end{array}$ & Có & $\begin{array}{l}\text { Đảm bảo nhu cầu tài chính của chính phủ và } \\
\text { các nghĩa vụ thanh toán nợ được đáp ứng một } \\
\text { cách kịp thời; phát triển thị trường nợ trong } \\
\text { nước }\end{array}$ & CSTK \\
\hline
\end{tabular}

Nguồn: Tác giả tự tổng hợp

Trong phần lớn các quốc gia, quản lý nợ công sẽ trải qua một vài giai đoạn phát triển điển hình: quản lý phi thị trường sau đó chuyển tiếp tới quản lý theo hệ thống thị trường định hướng, quản lý theo phương pháp tài sản - công nợ (Asset Liability Management - LAM) và cuối cùng là các dịch vụ tài khóa kết hợp với quản lý theo phương pháp tài sản - công nợ [15].

Trong giai đoạn đầu tiên, chính phủ dựa trên các công cư phi thị trường để tài trợ cho các khoản nợ đến hạn và cho phần lớn thâm hụt ngân sách. Một thị trường vốn trong nước chưa phát triển thực sự hạn chế việc lựa chọn các công cụ nợ của chính phủ. Chính phủ ở những thị trường như thế này thường tìm đến ngân hàng hoặc các tổ chức tài chính quốc tế, các quốc gia phát triển để vay với phần lớn là các khoản vay ưu đãi [16]. Trong giai đoạn này, ngay cả tài trợ trực tiếp từ ngân hàng trung ương cũng là một cách để chính phủ tìm kiếm nguồn tài trợ. Tiền tệ hóa khoản nợ là một cách để tài trợ cho thâm hụt nhưng sẽ để lại hậu quả tiêu cực cho nền kinh tế khi lạm phát tăng cao do lượng tiền cơ sở tăng lên. Trong giai đoạn vay mượn phi thị trường, các chức năng quản lý nợ bị hạn chế, nó chỉ bao gồm việc ghi nhận sổ sách các giao dịch vay mượn và hoàn trả nợ. Một hoặc vài cơ quan riêng biệt được trao quyền để quản lý nợ công chưa được thành lập. Quản lý nợ không tồn tại như một chính sách độc lập mà được tiến hành trong khuôn khổ của chính tiền tệ hoặc tài khóa [16]. Phương thức quản lý nợ công giai đoạn này thường được sử dụng bởi chính phủ các nước kém phát triển do thị trường vốn trong nước còn sơ khai, khó tiếp cận với thị trường vốn quốc tế cộng với năng lực quản lý hạn chế.

Giai đoạn hai của quản lý nợ công là việc chuyển tiếp lên hệ thống có tính thị trường. Đặc điểm chính của giai đoạn này đó là sự tín nhiệm đối với hệ thống quản lý nợ trong đó trọng tâm là hoạt động quản trị rủi ro và sự hợp nhất của quản lý nợ với quản lý toàn bộ dòng tiền của chính phủ. Trong giai đoạn này, cơ chế cơ bản để tài trợ ngân sách là thông qua việc phát hành trái phiếu chính phủ (TPCP) trên thị trường vốn trong nước. Sự phát triển của thị trường trái phiếu trong nước cũng cho phép chuyển đổi hệ thống vay mượn tài trợ chi tiêu công từ dựa chủ yếu trên hệ thống ngân hàng chuyển sang dựa chủ yếu trên thị trường vốn. Định hướng thị trường đương nhiên sẽ gây nên nhiều rủi ro tài chính hơn và do đó quản trị rủi ro trở thành một thành tố quan trong trọng quản lý nợ công giai đoạn này. Chính phủ bắt đầu thành lập các đơn vị, cơ quan riêng biệt gọi là cơ quan quản lý nợ công. Sự thành lập của đơn vị độc lập này cho thấy sự tách biệt hoàn toàn của hoạt động quản lý nợ công với chính sách tiền tệ và một phần của hoạt động này với chính sách tài khóa. Phương thức quản lý nợ công giai đoạn này đã có bước phát triển khi thị trường vốn trong nước bước đầu được hình thành và cơ sở pháp lý trở nên hoàn chỉnh hơn. Phương thức này thường được áp dụng ở các nước đang phát triển với năng lực quản lý đã bước đầu được cải thiện.

Giai đoạn thứ ba của quản lý nợ công chứng kiến chính phủ áp dụng cách tiếp cận quản lý tài sản - nợ (Asset Liability Managemetn - ALM) trong đó phối hợp các đặc điểm tài chính của tài sản và nợ chính phủ với nhau một cách hợp lý, từ đó quản lý rủi ro hiệu quả hơn. Quản lý nợ công trong giai đoạn này bắt đầu bao gồm không chỉ nợ hiện hữu mà còn có các khoản nợ tiềm năng, những thứ là nguồn cơn gây nên rủi ro tài khóa. Theo cách này, vị thế tài khóa thực sự của một quốc gia được bộc lộ. Doanh thu ngân sách 
tương lai, đại diện cho một thành tố chính trong tài sản của chính phủ và chúng thường được định danh dưới dạng đồng nội tệ, ít nhạy cảm đối với sự thay đổi lãi suất và lạm phát trong ngắn hạn lúc này sẽ được đưa vào trong danh mục quản lý. Nếu nợ hiện tại và nghĩa vụ nợ tiềm năng được tính theo đồng nội tệ, có kỳ hạn ngắn và không được chỉ số hóa theo lạm phát thì rủi ro của nợ chính phủ trước sự biến động của tỷ giá, lãi suất và lạm phát giảm một cách đáng kể [17]. Phương thức này đòi hỏi năng lực quản lý nợ cũng như cơ sở công nghệ ở mức độ nhất định để thu thập, xử lý và phân tích thông tin một cách kịp thời. Do đó nó được áp dụng ở một phần các quốc gia đang phát triển có thu nhập trung bình cao và các nước mới nổi.

Giai đoạn cuối cùng của quản lý nợ công đó là việc cung cấp các dịch vụ tài chính cho các cơ quan chính phủ và chính quyền địa phương cùng với phương thức $\mathrm{ALM}$. Phạm vi chức năng của DMO được mở rộng bao gồm cả đánh giá các khoản nợ của chính phủ, tư vấn các cơ quan khác của chính phủ về quản lý dòng tiền và rủi ro, tư vấn hoặc kiểm soát các dự án PPP, nhận tiền gửi hoặc kéo dài các khoản nợ của chính quyền địa phương và các cơ quan công quyền khác. DMO thông qua các dịch vụ như nhận tiền gửi và cho vay, cung cấp một lựa chọn thay thế trong giao dịch vốn ngân sách bên cạnh dịch vụ cung cấp bởi ngân hàng do đó làm gia tăng tiết kiệm chính phủ [18]. Quản trị tài sản và nợ chính phủ bây giờ bao gồm quản trị tài sản chính phủ chủ động và quản trị các quỹ chính phủ nhất định [19]. Đây là phương thức quản lý nợ công với năng lực quản trị và hệ thống công nghệ ở trình độ cao, đồng thời hệ thống luật pháp liên quan đến nợ công được xây dựng một cách đầy đủ và chặt chẽ. Do đó phương thức này thường được áp dụng ở một số nước phát triển.

Hình 2 minh họa sự kết hợp giữa mô hình quản lý nợ công trên thực tiễn với cách phân chia quản lý nợ công theo mức độ phát triển ứng với trình độ phát triển của mỗi quốc gia.
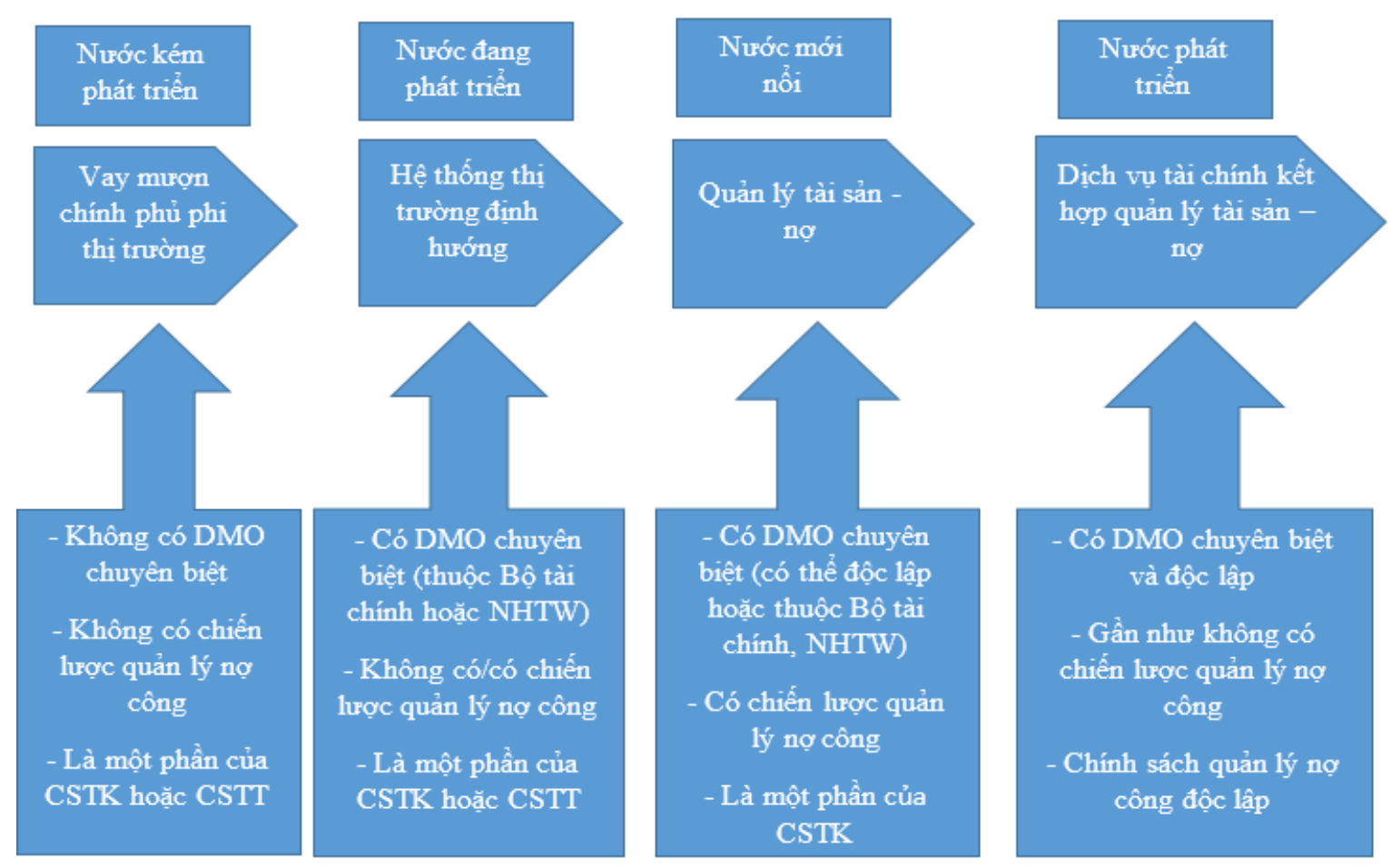

Hình 2. Các mô hình quản lý nợ công phù hợp theo từng giai đoạn phát triển của nền kinh tế.

Nguồn: Tác giả tự tổng hợp. 
Mô hình quản lý nợ công được xây dựng dựa trên trình độ phát triển của quốc gia có những bằng chứng nhất định trên thực tế. Theo khảo sát của WB năm 2013 tiến hành trên 117 quốc gia, có thể thấy hơn một nửa các quốc gia bao gồm cả nước có thu nhập cao, trung bình và thấp đều có chiến lược quản lý nợ công (tỷ lệ trung bình $60 \%$ ) [12]. Chất lượng chiến lược ở các quốc gia có thu nhập cao và trung bình cao hơn ở các quốc gia có thu nhập thấp [12]. Cụ thể các quốc gia có thu nhập càng cao thì xu hướng hình thành $\mathrm{DMO}$ chuyên biệt và độc lập trong chính phủ càng lớn. Mục tiêu của quản lý nợ công theo đó cũng được mở rộng từ chỉ tối thiểu hóa chi phí vay nợ lên kèm theo các mục tiêu phức tạp khác như kiểm soát rủi ro, duy trì nợ công bền vững; chính sách quản lý nợ công được độc lập hóa và hình thành cơ chế phối hợp với các chính sách vĩ mô khác để tạo ra ổn định tổng thể cho nền tài chính quốc gia. Ngoài ra cũng trong đánh giá về hoạt động quản lý nợ thường niên của mình (Debt Management Performance Assessment DeMPA), khi khảo sát kỹ hơn về các nội dung khác trong quản lý nợ công như thu thập, theo dõi, phân tích số liệu ở các nước thu nhập trung bình và thấp, WB đánh giá $41 \%$ các quốc gia thuộc nhóm này không đáp ứng được yêu cầu tối thiểu do mình đặt ra. Những kết quả khảo sát trên của WB cho thấy các nước thu nhập thấp và một phần các nước thu nhập trung bình gặp vấn đề đối với chất lượng của hoạt động quản lý nợ công trong khi các nước thu nhập cao làm tốt ở hầu hết các tiêu chỉ [13]. IMF (2018) đã chỉ ra nguyên nhân dẫn đến sự yếu kém trong quản lý nợ công ở các nước thu nhập thấp và trung bình đó là i) thiếu động lực để tạo ra cơ sở dữ liệu về nợ công đáng tin cậy dẫn đến số liệu được ghi nhận không chính xác, không kịp thời ii) quy trình thu thập số liệu không hoàn thiện dẫn đến thu thập thiếu dữ liệu iii) cơ sở vật chất và nguồn lực con người còn thiếu đặc biệt là cơ sở về công nghệ iv) trách nhiệm phân tán và thiếu sự phối hợp về mặt thể chế giữa các cơ quan, bộ phận trong chính phủ v) năng lực kiểm toán còn hạn chế [14]. Đây đều là những nguyên nhân mang đặc trưng của các nước có thu nhập thấp và trung bình, tuy nhiên điều này hoàn toàn có thể cải thiện được nếu quốc hội, chính phủ ở các nước này tập trung giải quyết trước hết là về mặt pháp lý (cơ cấu tổ chức, quy trình hoạt động) và sau đó là đầu tư nâng cao năng lực chuyên môn, công nghệ của hệ thống quản lý.

Có thể thấy mô hình quản lý nợ công ở các nước phát triển và chuyển đổi với công cụ hiện đại, cơ quan quản lý nợ công chuyên biệt và độc lập, hệ thống quản lý nợ công hoàn thiện có rất nhiều ưu điểm như đa dạng hóa công cụ tài trợ nợ, đảm bảo hoạt động nợ công diễn ra độc lập không bị tác động bởi các mục tiêu vĩ mô khác. Ngược lại, một mô hình như vậy đòi hỏi trình độ nguồn nhân lực và khả năng tổ chức rất cao. Đối với các mô hình ở các quốc gia đang phát triển thì mức độ tổ chức đơn giản hơn vì thế đòi hỏi trình độ nguồn lực không cao bằng, nhưng đổi lại cơ quản quản lý nợ công lại phụ thuộc vào BTC hoặc NHTW khiến chính sách quản lý nợ công dễ bị tác động bởi những mục tiêu vĩ mô khác. Ngoài ra công cụ tài trợ vốn chủ yếu dựa vào thị trường trái phiếu chính phủ cũng hạn chế phần nào nguồn cung ứng vốn và khả năng phân tán rủi ro nợ công.

Dựa trên việc phân tích các mô hình nợ công đang được thực hiện trên thế giới, có thể rút ra hai bài học kinh nghiệm cho Việt Nam như sau: i) cần xây dựng mô hình quản lý nợ công phù hợp với trình độ phát triển kinh tế và cụ thể là trình độ phát triển của thị trường tài chính. Mô hình quản lý nợ công với công cụ thị trường định hướng, có cơ quan DMO chuyên bộ phụ thuộc BTC, hệ thống pháp luật về quản lý nợ công có luật riêng và chiến lược quản lý là phù hợp với điều kiện của Việt Nam ii) dù thực hiện mô hình nào thì luôn phải chú trọng phát triển nguồn nhân lực (thu thập, xử lý, tổng hợp số liệu, dự báo, quản lý nợ chuyên nghiệp) và hoàn thiện hệ thống pháp luật về quản lý nợ công để luôn chủ động trong việc nâng cấp mô hình hiện tại.

\section{Mô hình quản lý nọ̣ công ở Việt Nam}

Trước năm 2009, Luật về Quản lý Nợ công chưa được ban hành. Đối với vay nợ trong nước, văn bản pháp lý cao nhất là Pháp lệnh số 
12/1999/PL-UBTVQH10 ngày 27/4/1999 của Uỷ ban Thường vụ Quốc hội về phát hành công trái xây dựng Tổ quốc và Nghị định số 141/2003/NĐ-CP của Chính phủ về phát hành trái phiếu Chính phủ, trái phiếu Chính phủ bảo lãnh và trái phiếu chính quyền địa phương. Đối với vay nợ nước ngoài, văn bản pháp lý cao nhất là Nghị định số 134/2005/NĐ-CP ngày 01/11/2005 của Chính phủ ban hành Quy chế quản lý vay và trả nợ nước ngoài, và Nghị định số 131/2006/NĐ-CP ngày 09/11/2006 của Chính phủ ban hành Quy chế quản lý và sử dụng nguồn hỗ trợ phát triển chính thức. Việt Nam cũng chưa có cơ quan chuyên biệt để quản lý nợ công, càng không có chiến lược quản lý nợ công. Như vậy có thể thấy trước năm 2009, Việt Nam theo mô hình quản lý nợ công đặc trưng của một nước kém phát triển, cho dù thực tế lúc đấy đối xử Việt Nam nhận được từ các tổ chức quốc tế là đối với nước đang phát triển. Điều này cho thấy tại thời điểm đó Việt Nam đang tụt hậu so với thế giới trong cách thức tổ chức quản lý nợ công.

Thấy rõ được ích lợi của một hệ thống quản lý nợ công bài bản, đặc biệt là sau cuộc khủng hoảng kinh tế 2008. Việt Nam trong năm 2009 đã ban hành Luật quản lý nợ công 2009 và mới nhất là là bản sửa đổi năm 2017, từ đó việc quản lý nợ công mới bắt đầu có tổ chức. Cục quản lý nợ thuộc BTC cũng đã được thành lập theo quyết định của 1168/QĐ-BTC ngày 22/5/2009. Ngay sau đó chiến lược quản lý nợ trung và dài hạn giai đoạn 2011 - 2020 tầm nhìn đển năm 2030 được thiết lập theo Quyết định 958/QĐ-TTg của thủ tướng chính phủ. Quy định nghiệp vụ quản lý nợ công chi tiết hơn còn được Chính phủ hướng dẫn qua Quyết định về quy chế và xử lý rủi ro đối với danh mục nợ công năm 2012 và Nghị định về nghiệp vụ quản lý nợ công năm 2018. Ngoài ra Quốc hội cơ quan quyền lực cao nhất cũng ấn định những tiêu chí quan trọng như trần nợ công, tạo cơ sở pháp lý cho việc giám sát thông qua Nghị quyết chi tiêu ngân sách giai đoạn 2016 - 2020, giai đoạn 2021 - 2025 và trước đó là kế hoạch phát triển kinh tế xã hội
2011 - 2015. Thậm chí vấn đề về nợ công còn được sự chỉ đạo sát sao từ Đảng thông qua Nghị quyết 07/NQ-TW ngày 18/11/2016 của Bộ Chính trị về chủ trương, giải pháp cơ cấu lại ngân sách nhà nước, quản lý nợ công để bảo đảm nền tài chính quốc gia an toàn, bền vững. Với nỗ lực phát triển thị trường trái phiếu trong những năm trở lại đây cộng với việc kiện toàn hệ thống pháp lý quản lý nợ công, chiến lược quản lý nợ công và tổ chức hoạt động quản lý nợ công, Việt Nam đang thực sự xây dựng mô hình quản lý nợ công đặc trưng đối với các nước đang phát triển trong giai đoạn quản lý nợ theo hệ thống thị trường định hướng. Hình 3 dưới đây mô tả mô hình quản lý nợ công hiện tại của Việt Nam.

Đây là mô hình quản lý như phân tích ở Hình 2 được nhiều nước đang phát triển sử dụng nhất là trong giai đoạn khi mới hình thành thị trường trái phiếu nói riêng và thị trường vốn nói chung ở trong nước. Cụ thể, Việt Nam đã có một cơ quan chuyên trách quản lý nợ công trực thuộc $\mathrm{BTC}$, có chiến lược quản lý nợ công với những chỉ tiêu an toàn được Quốc hội quy định và hoạt động quản lý nợ công được phối hợp chặt chẽ với chính sách tài khóa nhằm hướng đến nền tài chính quốc gia an toàn, bền vững.

Kết quả rõ rệt khi mô hình quản lý nợ công bài bản được hình thành đó là các số liệu nợ công được cập nhật thường xuyên trong bản tin nợ công công bố định kỳ bởi $\mathrm{BTC}^{3}$. Các đánh giá phân tích nợ công Việt Nam vì thế trở nên dễ dàng, thực tiễn và định lượng hơn [20]. Đây là cơ sở cho công tác điều hành quản lý nợ công trở nên hiệu quả. Kết quả là các chỉ tiêu nợ công luôn nằm trong ngưỡng an toàn được Quốc hội ấn định, trừ tỷ trọng nợ công nước ngoài hiện vẫn đang hơn ngưỡng một chút (xem bảng 2). Một biểu hiện khác cho việc quản lý nợ công hiệu quả đó là xếp hạng tín nhiệm quốc gia liên tục được nâng cao trong những năm gần đây. Đánh giá của $\mathrm{S} \& \mathrm{P}$, Fitch và Moody dành cho xếp hạng tín nhiệm của Việt Nam liên tục tăng trong giai đoạn 2009 - 2018 (trong giai đoạn này Moody thăng hạng Việt Nam từ B1 lên Ba3; Fitch BB- lên BB;

\footnotetext{
$\overline{3}$ Xem thêm về các bản tin nợ công của Việt Nam tại https://www.mof.gov.vn/webcenter/portal/btc/r/lvtc/qln
} 
S\&P giữ nguyên ở mức $\mathrm{BB})^{4}$. Đặc biệt, ngay trong thời điểm khó khăn do dịch Covid 19 gây ra thì xếp hạng tín nhiệm của Việt Nam là một trường hợp ngoại lệ khi vẫn duy trì được mức tín nhiệm không đổi với triển vọng ổn định trong tương lai [21].

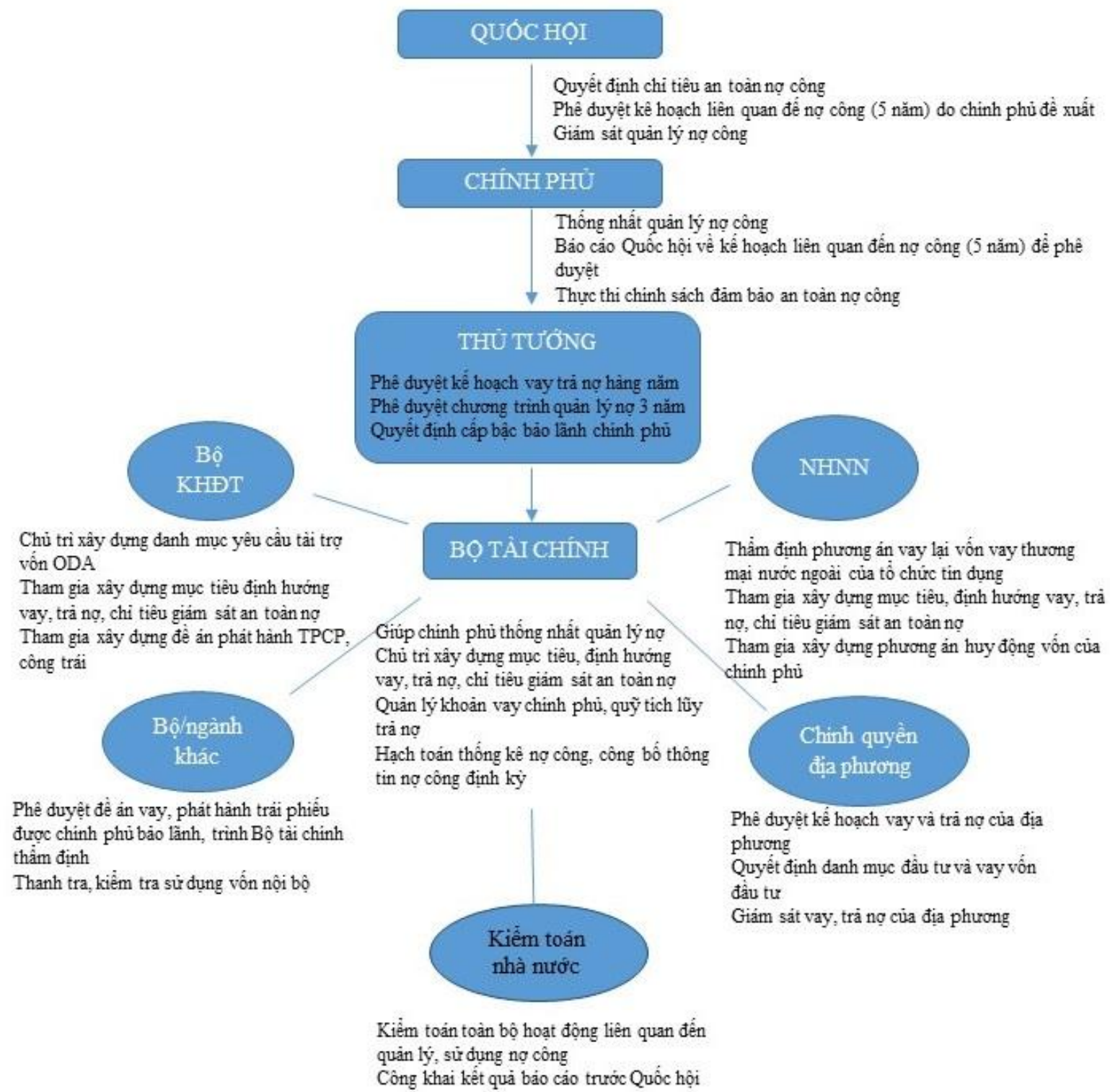

Hình 3. Mô hình quản lý nợ công ở Việt Nam.

Nguồn: Tác giả tổng hợp dựa trên Luật quản lý nợ công 2017.

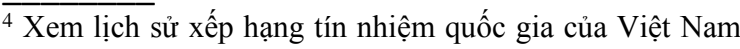
tại https://tradingeconomics.com/vietnam/rating
} 
Bảng 2. Tỷ trọng nợ công/GDP và nợ nước ngoài/tổng nợ công giai đoạn 2006 - 2018

Đơn vị: phần trăm

\begin{tabular}{|l|l|l|l|l|l|l|l|l|l|l|l|l|l|}
\hline & 2006 & 2007 & 2008 & 2009 & 2010 & 2011 & 2012 & 2013 & 2014 & 2015 & 2016 & 2017 & 2018 \\
\hline $\begin{array}{l}\text { Tỷ trọng } \\
\text { nợ } \\
\text { công/GDP }\end{array}$ & 45,9 & 49,7 & 47,9 & 51,0 & 54,3 & 54,9 & 50,8 & 54,5 & 58,0 & 61,0 & 63,7 & 61,4 & 58,4 \\
\hline $\begin{array}{l}\text { Ngưỡng } \\
\text { an toàn tỷ } \\
\text { troṇg nợ } \\
\text { công/GDP }\end{array}$ & 60 & 60 & 60 & 60 & 60 & 65 & 65 & 65 & 65 & 65 & 65 & 65 & 65 \\
\hline $\begin{array}{l}\text { Tỷ trọng } \\
\text { nợ nước } \\
\text { ngoài/tổng } \\
\text { nợ công }\end{array}$ & 58,2 & 56,9 & 52,4 & 57,5 & 55,8 & 43,3 & 45,8 & 50,2 & 54,6 & 58,0 & 59,0 & 59,7 & 40,6 \\
\hline $\begin{array}{l}\text { Ngưỡng } \\
\text { an toàn tỷ } \\
\text { trọng nợ } \\
\text { nước } \\
\text { ngoài/tổng } \\
\text { nợ công }\end{array}$ & 50 & 50 & 50 & 50 & 50 & 50 & 50 & 50 & 50 & 50 & 50 & 50 & 50 \\
\hline
\end{tabular}

Nguồn: Tác giả tổng hợp dựa trên số liệu của Bản tin nợ công Việt Nam giai đoạn 2006 - 2018.

Như đã phân tích ở trên, xét tổng hòa các điều kiện về hệ thống pháp lý, năng lực đội ngũ cán bộ và cơ sở công nghệ ở Việt Nam hiện nay thì mô hình quản lý nợ công đang có là phù hợp. Tuy nhiên vẫn còn những hạn chế tồn tại trong hệ thống quản lý nợ công của Việt Nam khi so sánh với những thực tiễn áp dụng tốt mô hình tương tự trên thế giới đó là: i) hệ thống pháp luật còn thiếu đặc biệt trong khâu kiểm tra, giám sát hoạt động quản lý nợ công của chính phủ ii) số liệu chưa được đầy đủ, thiếu cập nhật iii) thiếu nguồn nhân lực có chất lượng nên phần phân tích đánh giá và dự báo về nợ công phục vụ công tác quản lý còn yếu iv) hoạt động kiểm toán nợ công nói chung còn nhiều bất cập khiến nhiều vụ việc vi phạm chi tiêu ngân sách nhưng đến khi bại lộ thì kiểm toán mới vào cuộc [22-23].

Trong điều kiện ngày càng xuất hiện nhiều cú sốc thị trường (như khủng hoảng kinh tế 2008, đại dịch Covid 19), bối cảnh cần phải có sự can thiệp mạnh mẽ từ chính phủ cùng với đó là sự giảm dần các nguồn vốn vay ưu đãi từ bên ngoài khiến cho việc cải thiện chất lượng hệ thống quản lý nợ công là cần thiết hơn bao giờ hết.
Ngoài ra, ngay kể cả khi khắc phục được tất cả các hạn chế nêu trên thì mô hình quản lý nợ công tại Việt Nam trong dài hạn nếu giữ nguyên sẽ không thể theo kịp thực tiễn khi các công cụ tài chính tài trợ nợ công ngày càng trở nên phức tạp hơn, các cơ quan chính phủ sử dụng ngân sách với những mục tiêu riêng ngày càng chuyên biệt và dữ liệu về nợ công ngày càng nhiều. Điều này đòi hỏi việc chuyển đổi mô hình hiện tại sang mô hình quản lý nợ công tiệm cận các quốc gia mới nổi. Nếu khắc phục những hạn chế trong mô hình quản lý nợ công hiện tại là những mục tiêu trong ngắn hạn thì việc chuyển đổi mô hình quản lý nợ công sẽ là một mục tiêu trong dài hạn.

\section{Giải pháp xây dụ̣ng mô hình quản lý nọ̣ công hiệu quả ở Việt Nam}

Để khắc phục được những hạn chế hiện tại của hệ thống và dần dần chuyển sang mô hình quản lý nợ công hiện đại hơn, chính phủ Việt Nam cần thực hiện một số giải pháp sau đây:

Trước hết cần đào tạo nguồn nhân lực phù hợp, đáp ứng được nhu cầu về thu thập, xử lý số 
liệu, từ đó đưa ra các phân tích, dự báo chất lượng. Hoạt động này sẽ dễ dàng hơn nếu chúng ta có được sự trợ giúp kỹ thuật từ phía IMF, WB và các quốc gia có mô hình quản lý nợ công hiện đại hơn. Thứ hai, chính phủ cần phải cải thiện hệ thống thông tin, nâng cấp công nghệ để nhanh chóng cập nhật số liệu từ các bộ ban ngành, địa phương và công khai trên website (ví dụ website ckns.mof.gov.vn công khai số liệu ngân sách của tất cả các địa phương và bộ ban ngành). Việc minh bạch thông tin và cung cấp thông tin nhanh chóng vô hình chung sẽ tạo nên sức ép trong việc cải thiện chất lượng số liệu nợ công khi có nhiều bên có thể tham gia vào việc phản biện các vấn đề về số liệu. Thứ ba, phát triển thị trường trái phiếu nói riêng và thị trường vốn trong nước nói chung để dần gia tăng tỷ lệ nợ trong nước trong tổng nợ công. Đây là một trong những mục tiêu gián tiếp của quản lý nợ công khi nợ trong nước cơ bản sẽ có chi phí vay nợ thấp hơn nợ nước ngoài cùng với các rủi ro đi kèm ít hơn. Có thể thấy nợ nước ngoài trong tổng nợ công luôn ở ngưỡng vượt trần (dù ít), chưa kể chi phí đi vay nước ngoài sẽ ngày càng tăng khi Việt Nam không còn là một quốc gia có thu nhập bình quân đầu người thấp nữa. Hai yếu tố trên sẽ càng thúc đẩy chính phủ phát triển thị trường vốn trong nước ngày càng hoàn thiện. Thứ tư, chính phủ cần lên kế hoạch kiểm soát các khoản nợ tiềm tàng trong hoạt động quản lý nợ công càng sớm càng tốt. Những khoản nợ trong tương lai của quỹ bảo hiểm xã hội quốc gia, những khoản nợ trong dự án PPP... là những ví dụ của nợ tiềm tàng, những khoản nợ mà khi tình hình kinh tế xấu đi sẽ thật sự tạo thành gánh nặng cho chính phủ nhưng lại chưa được quy định trong nợ công theo luật và từ đó là hoạt động quản lý nợ công. Thứ năm, chính phủ cần định hướng rõ hơn sự phối hợp giữa ba chính sách tài khóa, tiền tệ và quản lý nợ công trong một thể thống nhất. Nội dung phối hợp này có thể được ghi trong chiến lược quản lý nợ công, đặc biệt là đối với các tình huống phải đánh đồi mục tiêu giữa các chính sách này. Cuối cùng, nhà nước nên kiện toàn hệ thống kiểm toán đối với ngân sách trong đó trao thêm nhiều quyền hơn nữa cho kiểm toán nhà nước trong việc cảnh báo cho chính phủ những khoản chi, khoản vay có thể dẫn đến rủi ro lớn hoặc vi phạm pháp luật về quản lý nợ công.

\section{Kết luận}

Quản lý nợ công là một trong những nhân tố quan trọng ảnh hưởng đến mức độ bền vững của nợ công, từ đó góp phần duy trì ổn định vĩ mô và thúc đầy tăng trưởng kinh tế. Trên thế giới đã hình thành bốn mô hình quản lý nợ công dựa trên thực tiễn triển khai ở nhóm các quốc gia theo trình độ phát triển của nền kinh tế. Đó là mô hình quản lý nợ công ở các nước kém phát triển, đang phát triển, chuyển đổi và phát triển. Mỗi một mô hình sẽ có một kỹ thuật quản lý, cơ cấu bộ máy quản lý và cách thức quản lý khác nhau. Hiện tại Việt Nam đang quản lý theo mô hình các nước đang phát triển với công cụ chính là thị trường trái phiếu chính phủ, có cơ quan quản lý chuyên trách nằm trong $\mathrm{BTC}$ và có luật cũng như chiến lược quản lý nợ công riêng biệt. Tuy nhiên với sự phát triển của nền kinh tế, đặc biệt là thị trường tài chính thì mô hình hiện tại bộc lộ một vài bất cập. Dựa trên muc tiêu là nâng cấp mô hình lên mô hình của các nước phát triển hơn, Việt Nam cần phải tập trung vào các giải pháp liên quan đến nhân lực, thông tin và thể chế. Trong đó phát triển thị trường trái phiếu chính phủ, nâng cao chất lượng nguồn nhân lực liên quan đến quản lý nợ công là những giải pháp có tính quyết định.

\section{Tài liệu tham khảo}

[1] D.Q. Bao, The science of Management and Organization Statistical Publishing House, Hanoi, 1999 (in Vietnamese),

[2] IMF, Defining the Government's debt and deficit, Working paper, WP/15/238, 2015.

[3] IMF, Revised guidelines for public debt management, IMF Policy paper, 2014.

[4] WB, Government debt management: Designing debt management strategies, Debt management learning \& training note, 2017.

[5] E. Currie, J. Dethier and E. Togo, Institutional arrangements for Public Debt Management, World Bank Policy Research Working Paper 3021, 2003. 
[6] E.C. Pascal, The debt office and the effective debt management functions: an institutional and operational framework, Public debt and Public Finance Working Paper, 2006.

[7] H. Bohn, Tax Smoothing with Financial Instruments, American Economic Review, 80/5 (1990) pp 1217-1230.

[8] J. Tobin, An Essay on the Principles of Debt Management, Fiscal and Debt Management Policies, 2 (1963), Reprinted in J. Tobin Essays in Economics, vol.1, Amsterdam: North Holland, 1971.

[9] E. Togo, Coordinating Public Debt Management with Fiscal and Monetary Policies: An Analytical Framework, World Bank Policy Research Working Paper, No. 4369, 2007.

[10] L. Hoogduin, B. Ozturk \& P.Wierts, Public debt managers' behavior: interactions with macro policies, DNB Working paper No.273, 2010.

[11] WB, Debt management performance assessment (DeMPA) methodology, 2015.

[12] R. Cabral, How strategically is public debt being managed around the globe? A survey on public debt management strategies, WB Financial advisory and Banking department report, 2015.

[13] C. Aslan, A. Ajazaj \& S.A. Wahidh, Study on Public debt management system and results of a survey on solutions used by debt management office, WB Financial advisory and Banking department report, 2018.

[14] IMF, G-20 note: Improving public debt recording, monitoring, and reporting capacity in low and lower middle-income countries: proposed reforms, 2018.

[15] A.A. Badurina, S. Svaljek, Public debt management before, during and after the crisis, Finance theory and practice, 36(1) (2012) 73 - 100.

[16] I. Storkey, Sound practice, in: M. Williams and P. Brione (Eds.), Government Debt Management:
New Trends and Challenge, Central Banking Publications Ltd, London, 2006, pp 300 - 325.

[17] G. Wheeler, Sound Practice in Government Debt Management, The World Bank Publication, Washington D.C, 2004. doi. 10.1596/0-8213-5073-0.

[18] National Treasury Management Agency, Ireland Information Memorandum 2010, National Treasury Management Agency, Dublin, 2010.

[19] M. Williams, The growing responsibilities of debt management offices, in: M. Williams, P. Brione (Eds.), Government Debt Management: New Trends and Challenge, Central Banking Publications Ltd, London, 2006, pp 258 - 273.

[20] H.N. Au, Public debt management in Vietnam in the international integration period (in Vietnamese), https://hcma.vn/Uploads/2018/8/8/Hoang\%20Ngo c\%20Au\%20-\%20Luan\%20an\%20\%20CN\%20Quan\%20ly\%20kinh\%20te.pdf, 2018 (accessed 20 August 2020).

[21] T. Phung, Firmly maintaining the country's credit rate (in Vietnamese), http://tapchitaichinh.vn/sukien-noi-bat/tiep-tuc-giu-vung-muc-xep-hang-tinnhiem-quoc-gia-325601.html, 2020 (accessed 21 August 2020).

[22] N.T. Binh, The factors affecting the efficiency of public debt management in Vietnam (in Vietnamese),

http://www.tapchicongthuong.vn/bai-viet/cac-yeuto-anh-huong-toi-hieu-qua-quan-ly-no-cong-oviet-nam-73005.htm, 2020 (accessed 22 August 2020).

[23] T. Anh, Six solutions for public management in the new context (in Vietnamese), http://tapchitaichinh.vn/su-kien-noi-bat/6-giaiphap-quan-ly-no-cong-trong-boi-canh-moi308263.html, 2019 (accessed 23 August 2020). 